\title{
Las ciudades latinoamericanas como objeto de estudio o marco espacial de análisis*/
}

\author{
The Latin-American Cities as an Object \\ of Study or Spatial Frame of Analysis
}

\author{
Emilio José Luque Azcona \\ ORCID iD: https://orcid.org/0000-0002-0588-4891 \\ Universidad de Sevilla
}

\begin{abstract}
El propósito de este trabajo es analizar la presencia de estudios relativos al medio urbano latinoamericano en los artículos publicados por la revista Anuario de Estudios Americanos, durante el período comprendido entre los años 1944 y 2018. Con ello pretendemos poner de relieve el aporte y la relevancia de estas investigaciones, en el contexto de las realizadas sobre historia urbana de América Latina por investigadores de diferentes disciplinas, tanto desde la propia región como desde universidades y centros de investigación de Estados Unidos de Norteamérica y Europa.

Palabras Clave: Historia Urbana; Historiografía; América Latina; Ciudades.

The purpose of this paper is to analyze the presence of studies related to Latin-American urban environment in the articles published by the magazine Anuario de Estudios Americanos between 1944 and 2018. With this purpose we intend to highlight the contribution and the relevance of these articles, in the context of the studies related to Urban History of Latin America which have been done from different disciplines, both from the region itself and from universities and research centers in the United States of America and Europe.
\end{abstract}

KeYworDs: Historiography; Urban History; Latin America; Cities.

Copyright: () 2018 CSIC. Este es un artículo de acceso abierto distribuido bajo los términos de la licencia de uso y distribución Creative Commons Reconocimiento 4.0 Internacional (CC BY 4.0).

* Trabajo realizado en el proyecto de investigación financiado por el MINECO, referencia HAR2015-66152-R. 
Este artículo analiza la presencia de estudios sobre el medio urbano latinoamericano publicados en la revista Anuario de Estudios Americanos. Con ello pretendemos poner de relieve el aporte y la relevancia de estos trabajos en el contexto de las investigaciones que sobre historia urbana de América Latina se han hecho por parte de investigadores de diferentes disciplinas. ¿En qué momento se aprecia una mayor presencia de estos artículos?, ¿de qué disciplinas proceden sus autores?, ¿qué temáticas, ámbitos geográficos y marcos cronológicos tratan?, ¿en qué medida existe una correspondencia con las diferentes corrientes de estudio que sobre lo urbano se fueron dando a lo largo del período analizado?

Para responder a estos interrogantes, en un primer apartado presentamos, a modo de síntesis, las diferentes corrientes y principales autores que en el plano internacional contribuyeron al desarrollo de la historia urbana. A continuación, se hace lo mismo con la que se refiere a América Latina, pasándose en el tercer apartado a la revisión de los artículos que tienen como objeto de análisis la ciudad o lo urbano como marco espacial y que han sido publicados en el Anuario de Estudios Americanos durante sus 75 años de existencia.

\section{De la historia de ciudades a la historia urbana y del urbanismo}

Son numerosos los especialistas de diferentes disciplinas que han destacado el carácter pluridisciplinar del estudio de los espacios urbanos. ${ }^{1}$ Como consecuencia de ello han existido enfoques sectoriales y parciales que no han sido óbice para que los especialistas que tienen a la ciudad como objeto de estudio coincidan «en lugares de interés común en los que los intercambios cognitivos y metodológicos son obligados», siendo el urbanismo, la historia urbana y la geografía urbana las que han tenido «una vocación de aproximación más amplia y completa al conjunto del espacio urbano». ${ }^{2}$

Como ha puesto de relieve el geógrafo Horacio Capel, la historia urbana es un campo que en buena medida se ha desarrollado desde fuera de la disciplina histórica, principalmente desde el derecho, el urbanismo, la geografía y la historia del arte, siendo durante las primeras décadas del

1 Uno de los pioneros, en este sentido, fue el catedrático de Historia de la Arquitectura, Fernando Chueca Goitia. Chueca Goitia, 1968, 7.

2 Delgado Viñas, 2016, 118. 
siglo XX cuando surgieron diferentes líneas de interés por las ciudades como un fenómeno de estudio específico. En este sentido, apunta que durante mucho tiempo los historiadores no se interesaron por «el cuadro físico en el que se desarrollaban los sucesos que estaban narrando», al estar más interesados por las «dimensiones y las dinámicas sociales, políticas, económicas o culturales», por lo que ha sido poco el interés que han mostrado por aspectos relacionados con la «producción de la forma urbana y sus características, el proceso físico de urbanización, la morfología, la lógica de la producción del espacio construido». ${ }^{3}$

La preocupación por una Urban History, entendida como área específica con personalidad propia, apareció en los ámbitos anglosajones en los años cincuenta del siglo pasado. En este punto, el urbanista venezolano Arturo Almandoz, tras diferenciar la historia urbana - dedicada a la ciudad y el proceso de urbanización - de la historia del urbanismo — referida al urbanismo técnico (conocida en los ámbitos anglosajones como Planning History)—, expone que la fase de constitución y consolidación de la historiografía urbana en el eje angloestadounidense se produjo cuando los historiadores norteamericanos y británicos se pasaron de las biografías de ciudades al análisis de procesos, al tiempo que ponían énfasis en los enfoques comparativos y «la relación de dimensiones demográficas, territoriales, económicas y sociales». ${ }^{4}$

La década de 1960 sería decisiva en la conformación de la historia urbana como campo de estudio en diferentes países, al tomarse conciencia de la importancia del papel desempeñado por las ciudades en el cambio social y económico, siendo varios los historiadores norteamericanos que empezaron a explorar la historia de la ciudad como forma de dar respuesta a la crisis urbana por entonces existente. ${ }^{5} \mathrm{~A}$ mismo tiempo, en algunas universidades del Reino Unido aparecieron grupos de trabajo sobre historia urbana, destacando en este sentido algunas como la de Leicester, con Harold James Dyos al frente, y Glasgow, con Sydney George Checkland. También se celebraron eventos académicos, como la primera conferencia sobre esta materia que tuvo lugar en 1966, en la que participaron principalmente historiadores,

3 Capel, 2009.

4 Ver Almandoz, 2008, capítulo I, y Castillo Fernández, 2009.

5 Capel, 2009. Entre ellos se encuentra Stephan Thernstrom, editor junto con el sociólogo Richard Sennett del libro Nineteenth-Century Cities. Essays in the New Urban History (1969), en el que se publicaron los resultados de las conferencias celebradas en 1968 en la Universidad de Yale, relativas a pequeñas comunidades y grandes ciudades de Estados Unidos de Norteamérica, aunque también de Canadá, Inglaterra, Francia y Colombia. 
geógrafos y sociólogos. ${ }^{6}$ Para Dyos, entre los objetivos de estudio de la historia urbana se encuentran tanto los procesos urbanos, los factores y elementos que dan lugar a la evolución de una ciudad o grupos de ciudades, como las relaciones entre espacio urbano y la sociedad que lo habita. ${ }^{7}$

Sergio Miranda, al analizar el desarrollo de la historia urbana en México, destaca las afirmaciones realizadas en esos momentos por Roy Lubove, profesor de la Universidad de Pittsburgh, que se lamentaba por el hecho de que los historiadores de Estados Unidos confundieran dicha disciplina con todo aquello que sucedía en las ciudades, por lo que propuso interpretarla «como el estudio del proceso de construcción de la ciudad en el tiempo», debiendo por ello preocuparse los historiadores — a su entender- por el amplio rango de mecanismos de construcción de la ciudad, o lo que es lo mismo, «por las decisiones de individuos o instituciones que han influido la estructura y formas urbanas, así como por el análisis de las tendencias sociales, económicas y tecnológicas más amplias que han determinado la naturaleza de esas decisiones». ${ }^{8}$

No obstante, durante los años setenta, en unos momentos en los que la conciencia sobre la importancia del patrimonio cultural fomentaba la conservación de centros históricos y la enseñanza de la historia arquitectónica en medios académicos y profesionales, ${ }^{9}$ la historia urbana sería criticada por diferentes historiadores que veían en ella «un campo con un contenido mal definido, sin coherencia», por incluir «cualquier cosa que se refiera a la ciudad». De hecho, en los años ochenta, a pesar de que la misma contaba ya para entonces con un campo de estudio consolidado, continuaba buscando todavía una definición formal y una «coherencia interna»..$^{10}$

Para Bernard Lepetit fue precisamente en los años ochenta cuando la historiografía francesa consolidó a la ciudad como objeto de estudio de la historia, al tiempo que la reconocía como sujeto de la misma. ${ }^{11}$ El desarrollo de la historia urbana se produciría en España también en esos momentos, encontrándose entre los factores que impulsaron su aparición, de manera parecida a lo sucedido en países anglosajones, la preocupación por las transformaciones y los problemas generados con la urbanización acelerada

6 Capel, 2002, 43.

7 Capel, 2009. Sobre el aporte realizado por Dyos a la historia urbana del Reino Unido consultar Mandelbaum, 1985.

8 Miranda Pacheco, 2012, 352.

9 Almandoz, 2011, 129.

10 Capel, 2009.

11 Al respecto consultar Lepetit, 1992. Citado por Miranda Pacheco, 2012, 352. 
de los años sesenta, al entenderse entonces «que la investigación de los hechos urbanos con visión retrospectiva podía ayudar a entender la ciudad actual». ${ }^{12}$

El arquitecto Fernando de Terán Troyano, al referirse a la historia urbana moderna de España, distingue varias fases en su desarrollo: tras las escasas individualidades que empezaron a sentar las bases, fueron las influencias alemana y francesa las más destacadas durante las décadas de 1930 y 1940, dejando paso en los años cincuenta, sesenta y setenta, a la anglosajona y, también durante esta última década y la de los ochenta, a la italiana en algunos campos sectoriales. En relación a los enfoques conceptuales y metodológicos empleados por las disciplinas implicadas en el estudio de la historia urbana, Terán destaca que partieron de «enfoques generales de base empírica e interpretación bastante intuitiva, que pronto desarrollaron aspiraciones cientifistas, pasando después (ya en los años cincuenta y sesenta) a una etapa caracterizada por interpretaciones teóricas de base funcionalista». A continuación, «en pleno éxito de los enfoques estructuralistas, vendría la aspiración a los grandes acopios de información numérica, fundamentalmente estadística», al tiempo que durante las décadas de 1960 y 1970 «se abrieron impetuosamente camino los enfoques de orientación marxista, con la intención puesta en demostrar la relación entre las formas de organización espacial y los sistemas de organización económica y social». Por otra parte, Terán menciona también el papel desempeñado por departamentos de universidades, algunos institutos del Consejo Superior de Investigaciones Científicas, el desaparecido Instituto de Estudios de Administración Local (IEAL) y el Centro de Estudios Históricos de Obras Públicas y Urbanismo (CEHOPU), para la promoción de investigaciones y publicaciones relacionadas con este campo de estudio. ${ }^{13}$

Junto con el propio Fernando de Terán, con obras como la titulada Ciudad y urbanización en el mundo actual (1969), entre los grandes impulsores de la historia urbana en España estuvieron también el arquitecto Fernando Chueca Goitia, con obras «a caballo entre la crítica arquitectónica, la crónica y la historia urbanas», y el historiador del arte Antonio Bonet Correa. ${ }^{14}$ Este último abrió nuevos caminos a la investigación de su disciplina y del urbanismo en España, acercándose a la historia con el objetivo

12 Terán, 1996, 88 y 89.

13 Ibidem, 91-93.

14 Almandoz, 2011, 126-127. 
de «conocer algunas de las claves que permiten entender el presente», en un esfuerzo por comprender «para proyectar mejor el futuro». ${ }^{15}$

Puede afirmarse que la presencia de historiadores en la nueva historia urbana española surgida a mediados de los años setenta fue escasa, siendo principalmente geógrafos, arquitectos e historiadores del arte sus impulsores. ${ }^{16}$ Carlos Sambricio y Carmen Delgado Viñas han puesto de relieve el hecho de que, en las investigaciones desarrolladas hasta los años ochenta, los historiadores interesados por el estudio de lo urbano pusieron el acento en la dimensión temporal, concibiendo la ciudad como contexto físico o escenario en el que interactúan los diferentes sectores de la sociedad y tienen lugar las transformaciones contemporáneas más destacadas y los hechos históricos. ${ }^{17}$ Para Fernando de Terán, este tipo de investigaciones no configuraban «un panorama coherente y unificado», puesto que habían sido abordadas algunas veces «con carácter claramente sectorial, desde múltiples campos disciplinares» y otras con «vocación generalista», en ambos casos adoptando formas diferentes, según las limitaciones temporales y espaciales aplicadas, siendo escasas las síntesis generales. ${ }^{18}$

Volviendo al plano internacional, entre los tipos de estudios que tuvieron un desarrollo más destacado durante los años ochenta relacionados con las ciudades se encuentran los de tipo transnacional o, de forma más específica, transatlántico, que establecieron comparaciones entre los diferentes modos de planificación de diversos países y de las formas de desarrollo de sus principales centros urbanos, subrayando «la intensidad de las redes internacionales y de la circulación de ideas y modelos urbanísticos durante las primeras décadas del siglo XX», momento durante el cual se establecieron las bases teóricas del planeamiento y las primeras formas de acción urbana previas a las grandes transformaciones experimentadas por las ciudades europeas y americanas a partir de la Segunda Guerra Mundial. ${ }^{19}$

A partir de los años noventa se produciría una fragmentación de los trabajos de historia urbana y urbanística, que Arturo Almandoz interpreta

15 Capel y Tatjer, 1992, 7-13. A todo ello contribuyó también con sus publicaciones, como la titulada Morfología y ciudad (1978), y con la celebración de encuentros científicos como el primer simposio sobre «Urbanismo e Historia Urbana en España» a fines de los años setenta y el segundo, sobre «Urbanismo e Historia Urbana en el mundo hispano», celebrado en 1982. Al respecto consultar Bonet Correa, 1979 y 1985.

16 Almandoz, 2011, 128.

17 Sambricio, 1996, y Delgado Viñas, 2016, 119.

18 Terán, 1996, 93.

19 Fernández Águeda, 2016, 32. 
como «un rechazo a las leyes interpretativas de inspiración weberiana, marxista o de la escuela de los Anales, aplicadas a grandes períodos históricos y/o a bloques geográficos o vastas extensiones territoriales», con estudios en los que «se enfatizan la contingencia y autonomía de las formas culturales». En este sentido, considera que esta corriente se alimenta de aportes provenientes de la «nueva historia cultural» de Peter Burke, de la visión sobre producción y representación del espacio urbano de Henri Lefebvre, y de aspectos metodológicos tomados de Michel de Certeau, Jürgen Habermas, Pierre Bordieu y David Harvey. ${ }^{20}$

Como consecuencia de ello, numerosos historiadores escogieron la ciudad en sí misma como objeto de sus investigaciones, hecho que ha propiciado que el espacio urbano pase a ser entendido, también desde esta disciplina, como un producto «que se forma y evoluciona bajo las mismas leyes que rigen el sistema social que lo construye». El interés de los estudios históricos urbanos se ha orientado al análisis de tres aspectos principales: el crecimiento de la ciudad y la expansión del espacio urbano, la construcción de las infraestructuras y servicios públicos y los poderes urbanos y las instituciones de gobierno local, para el período de transición de la ciudad moderna a la contemporánea, que para el caso español comprende los siglos XVIII, XIX y XX. ${ }^{21}$

Simon Gunn destaca como los principales temas analizados para la historia moderna de Europa y Norteamérica a los conflictos sociales (el París revolucionario), el gobierno de la ciudad (los grandes ayuntamientos europeos) y las relaciones entre esta y el Estado (luchas por la independencia de las ciudades frente a las autoridades). También pone de relieve el interés especial que la historia urbana moderna ha prestado a los grupos subordinados y a su capacidad para actuar «constriñendo o limitando el ejercicio del poder desde arriba». ${ }^{22}$

Las transformaciones experimentadas por los espacios urbanos en el contexto de la globalización desde la década de 1990 repercutieron en la aparición nuevos enfoques en los estudios sobre ciudades, como el que se interesa por el análisis de la dimensión global de las ciudades bajo el enfoque de la competencia y la competitividad. Como consecuencia de ello, se

20 Entre los trabajos más influyentes de estos autores destacan el de Henri Lefebvre sobre $\mathrm{La}$ révolution urbaine (1970); el de Michel de Certeau sobre L'écriture de l'histoire (1975), o el de David Harvey sobre The Condition of Postmodernity. An Enquiry into the Origins of Cultural Change (1990). Almandoz, 2003, 147-148.

21 Delgado Viñas, 2016, 119.

22 Gunn, 2013, 101 y 103. 
pasó a adoptar una perspectiva global y mundial que ha sustituido a la forma de estudiar las ciudades en términos de sistemas cerrados, estatales o regionales, si bien se produjo también de forma paralela una revalorización del lugar y del conocimiento de la dinámica urbana local. ${ }^{23}$ Dentro de la historia urbana estas tendencias se han reflejado en aspectos como el refuerzo de la idea de red como esencial para la comprensión del crecimiento y del papel económico de las ciudades en determinados períodos del pasado, también de su configuración política y social interna. ${ }^{24}$ En la actualidad el campo de la historia urbana, cultivado tanto por historiadores como por especialistas de otras disciplinas, cuenta con un amplio reconocimiento.

\section{Historia urbana de América Latina}

A diferencia de lo expuesto para países como Gran Bretaña y Estados Unidos, en los que la historia urbana derivó de corrientes sociales y económicas, para el caso latinoamericano la historia del arte fue la primera en proveer el sustrato para una historia urbana de la región. En este sentido, Arturo Almandoz destaca la celebración de los Congresos Panamericanos de Arquitectos a partir de 1924 y la publicación entre sus resultados de una serie de trabajos sobre arte y arquitectura hispanoamericanos realizados por los argentinos Martín Noel y Mario Buschiazzo, el peruano Emilio Harth-Terré y el mexicano Manuel Toussaint. También las publicaciones periódicas que sirvieron de foro para ese primer grupo de historiadores del arte, como Anales del Instituto de Investigaciones Estéticas de la Universidad Nacional Autónoma de México (1937), los Anales del Instituto del Arte Americano e Investigaciones Estéticas de la Universidad de Buenos Aires (1948), los cuadernos de Arte en América y Filipinas de las Universidades de Sevilla y México (1935), la colección de planos coloniales del Archivo General de Indias editados por Diego Angulo Íñiguez en Sevilla entre 1933 y 1939, y la Historia del Arte Hispanoamericano (1945-1956) publicada por Diego Angulo Íñiguez junto con Enrique Marco Dorta y Mario Buschiazzo. ${ }^{25}$ De forma paralela, en el ámbito académico fueron pioneras en la

23 Delgado Viñas, 2016, 126.

24 Gunn, 2013, 103 y 104.

25 Almandoz, 2011, 115-116. Estos trabajos, junto a otras recopilaciones que incluyen mapas y planos de ciudades hispanoamericanas, serían de gran importancia para el desarrollo futuro de investigaciones sobre la historia del urbanismo de la región. Entre las aportaciones tempranas se encuentran también las realizadas por el que fuera jefe del Archivo General de Indias, Pedro Torres 
institucionalización de la enseñanza del urbanismo tanto la Universidad del Litoral de Rosario, con la creación de una Cátedra de Urbanismo en 1929, como la Escola Nacional de Belas Artes de Brasil, con la reforma impulsada en ella por Lùcio Costa a inicios de la década de $1930 .{ }^{26}$

A partir de la Segunda Guerra Mundial el fenómeno urbano en América Latina se mostraba al mundo como «insólito e irrefrenable», por el acelerado crecimiento de las ciudades como consecuencia de la emigración campo-ciudad, las elevadas tasas de crecimiento vegetativo y la inmigración, provocando una serie de cambios de orden económico y social que centraron el interés de investigadores de diferentes disciplinas, primero de Europa y Estados Unidos, rápidamente también de la región. ${ }^{27}$ Determinados factores contribuirían, a inicios de la década de 1960, al impulso de los estudios sobre el urbanismo latinoamericano con una perspectiva global. Entre ellos se encuentra la constitución, en 1957, de la Sociedad Interamericana de Planificación (SIAP), una corporación civil de interés colectivo y carácter internacional, sin fines de lucro y abierta a los profesionales interesados «en la planificación democrática y participativa para lograr un desarrollo económico con equidad social y territorial», que sería reconocida por el Consejo Económico y Social de la ONU como Organismo No Gubernamental con estatus consultivo. ${ }^{28}$ En 1960 la SIAP describiría una serie de lineamientos para la consolidación de programas e institutos de formación de profesionales en la temática sobre planificación regional y urbana, iniciativa que en el caso de Argentina impulsaría el arquitecto Jorge Enrique Hardoy, primero desde el Instituto de Planeamiento Regional y Urbano del Litoral (IPRUL), entre 1962 y 1965, y con posterioridad en el Centro de Estudios Urbanos y Regionales (CEUR), entre 1956 y 1976, ${ }^{29}$ al retornar a su país tras graduarse en la Universidad de Harvard con un doctorado en Planeamiento Urbano y Regional.

Lanzas, a quien se deben los seis primeros catálogos de la serie geográfica de la sección Mapas y Planos del mencionado archivo; el primero de ellos se publicó en 1897 referido a Filipinas, encontrándose entre los restantes el titulado Relación descriptiva de los mapas, planos, etc., de México y Florida existentes en el Archivo General de Indias (1900). Cabe mencionar también: «La Cartografía colonial americana», publicado por Germán Latorre en el Boletín del Centro de Estudios Americanistas (1915); Mapas y planos referentes al Virreinato del Río de la Plata conservados en el Archivo General de Simancas, realizado por José Torre Revello (1938); Planos de la ciudad de México, siglos XVI y XVII, de Manuel Toussaint, Federico Gómez de Orozco y Justino Fernández (1938); o Cartografía de Venezuela. 1635 1946: selección de los principales planos publicados hasta la fecha (1946).

26 Almandoz, 2003, 127.

27 Panadero Moya, 2001

28 Camacho, 2007, 268.

29 Monti, 2014-2015. 
En el año 1964 Hardoy publicó su libro sobre Ciudades Precolombinas, que llenó de asombro tanto a historiadores, como a urbanistas y arqueólogos. ${ }^{30}$ En los años siguientes su aporte a la historia urbana se consolidaría en los diferentes seminarios que organizó por todo el continente, especialmente en el marco de los Congresos Internacionales de Americanistas, de forma conjunta con Richard P. Schaedel (profesor del Departamento de Antropología de la Universidad de Texas) y Richard Morse (profesor de Historia de la Universidad de Yale), cuyos resultados fueron parcialmente publicados en libros que abarcaban una visión integrada de la historia urbana americana desde los tiempos prehispánicos hasta lo contemporáneo, en unos momentos en los que las revistas de arquitectura empezaban a dar un creciente espacio a estudios de caso o de períodos específicos sobre temas de historia urbana. ${ }^{31}$

Hardoy presidió la SIAP entre 1966 y 1970, al tiempo que participaba, junto a otros expertos en arquitectura latinoamericana, en reuniones patrocinadas por la UNESCO, como la de Lima de 1967, en la que se trazaron los lineamientos principales de la serie América Latina en su cultura, consistentes en la consideración de América Latina como un todo y una unidad cultural y en analizar a «la región a partir de su contemporaneidad, remontándose en el pasado, eso sí, cuando sea necesario para comprender el presente». ${ }^{32}$ No hay que olvidar que en ese período, concretamente en 1967, tuvo lugar el coloquio o reunión para la conservación y utilización de monumentos y sitios de valor histórico y artístico en la ciudad de Quito, por iniciativa de la Organización de Estados Americanos (OEA). De ella saldría la Carta de Quito, documento de gran relevancia para el devenir del patrimonio cultural latinoamericano, que entre otras cosas consideraba «la revalorización y conservación del patrimonio cultural dentro del proceso de desarrollo económico» que Latinoamérica vivía en esos momentos. ${ }^{33}$ Es entonces cuando lo «histórico» comenzaba a adquirir una dimensión más

30 Gutiérrez, 1995, 9. En la parte de los agradecimientos del mencionado libro, Hardoy expuso que había sido en 1955 cuando comenzó a desarrollar la idea de escribir un trabajo sobre las ciudades de América Latina y que desde entonces había dedicado muchos meses a viajar por la región y a leer y clasificar una ingente cantidad de fuentes con ese fin. Hardoy, 1964, 7-11.

31 Almandoz, 2011, 121-122. Entre ellos se encuentran los libros El proceso de urbanización en América Latina desde sus orígenes hasta nuestros días (1969) y Ensayos histórico-sociales sobre la urbanización en América Latina (1978).

32 Así se expresa en el prefacio del libro América Latina en su arquitectura, en el que Hardoy escribe los capítulos relativos al proceso de urbanización, que incluye un sub-apartado relativo al proceso histórico, así como al de las áreas metropolitanas. Segre, 1975, I.

33 González-Varas, 2005, 501. 
amplia, al tiempo que la memoria histórica de una comunidad se entendía que «la constituyen las calles, los edificios, los objetos que pueden ayudar a evocar y reafirmar ese pasado». ${ }^{34}$

En el caso de Hardoy, sería a fines de la década de 1970 cuando comenzaría a incorporar a su obra aspectos relativos a la relación entre la ciudad, su historia y la preservación, empezando a pensar a partir de entonces en las cuestiones patrimoniales de una forma más sistemática. En este sentido, en 1980 el Programa de las Naciones Unidas para el Desarrollo contactó con él para que formara parte de un grupo de expertos que estaba realizando un estudio sobre centros históricos de ciudades latinoamericanas, en el que trabajaba Sylvio Mutal con otros investigadores. Como resultado del trabajo realizado se publicaron varios volúmenes, como el relativo al Impacto de la urbanización en los centros históricos latinoamericanos (1983), iniciándose con ello, como destaca el arqueólogo argentino Daniel Schávelzon, «una nueva etapa del pensamiento patrimonial en la región». ${ }^{35}$

Entre las publicaciones que durante los años setenta contribuyeron también a dar una visión continental del desarrollo histórico urbano de la región, se encuentran la de Manuel Castells sobre Imperialismo y urbanización en América Latina (1973) y la compilada por Marta Schteingart titulada Urbanización y dependencia en América Latina (1973), ambas bajo el enfoque la de la teoría de la dependencia, consolidada ya para entonces como «una explicación alternativa básicamente marxista frente al

34 Arias, 1994, 29.

35 Schávelzon, 1993. Precisamente, dentro de los aportes realizados por Hardoy, Ramón Gutiérrez destaca la integración entre la historia urbana de América Latina y la planificación, dejando con ello la primera de ser «un pequeño capítulo, colocado por compromiso al inicio del voluminoso expediente urbano», en el que se incluía «sin mucha convicción, una secuela de fechas históricas, que solían estar desconectadas de todo hecho de transformación física, económica y social de la ciudad». También, una visión de la historia urbana en el contexto regional y territorial, la proyección desde la planificación a la preservación del patrimonio, la apertura desde lo «histórico» a las dimensiones sociales, económicas y culturales del presente y, por último, la promoción de los estudios de historia urbana en América. Gutiérrez, 1995, 9-12. Entre las numerosas publicaciones realizadas Hardoy se encuentran también algunos trabajos como los que a continuación se exponen, cuyos títulos dan una idea de las temáticas tratadas: Hardoy, Jorge E. y Tobar, Carlos, La urbanización en América Latina (1969); Hardoy, Jorge E. y Aranovich, Carmen, «Urbanization in Spanish America between 1580 and 1630» (1969); Hardoy, Jorge E., Las ciudades en América Latina. Seis ensayos sobre la urbanización contemporánea (1972); Schaedel, Richard P., Hardoy, Jorge E. y Scott-Kinzer, Nora, Urbanization in the Americas from its Beginning to the Present (1978); Hardoy, Jorge E. y Morse, Richard P., Nuevas perspectivas en los estudios sobre historia urbana latinoamericana (1989); Hardoy, Jorge E., Cartografía urbana colonial de América Latina y el Caribe (1991); Hardoy, Jorge E., Gutman, Margarita y Mutal, Sylvio, Impacto de la urbanización en los centros históricos de Iberoamérica: tendencias y perspectivas (1992). 
desarrollismo de corte capitalista». ${ }^{36}$ Como consecuencia del proceso de crítica desarrollado por investigadores y docentes en los años 1971 y 1972 en las escuelas de arquitectura de universidades colombianas, Emilio Pradilla y Carlos Jiménez publicarían, también en 1973, Arquitectura, urbanismo $y$ dependencia neocolonial, con el objetivo de demostrar, como mencionan a la hora de justificar ese trabajo, que su práctica técnica era «un instrumento al servicio del Capital en su tarea de explotación y dominación social». ${ }^{37}$

Otra obra destacada que también contribuyó a esa visión continental, pero al margen «de los principios marxistas y agenda economicista de la escuela» ${ }^{38}$ fue la realizada por el historiador argentino José Luis Romero, Latinoamérica: las ciudades y las ideas (1976), obra que se constituiría en uno de los clásicos de la historiografía latinoamericana. En ella su autor analiza la historia de las ciudades de la región para entender «el sentido de la historia general de Latinoamérica», sistematizando un largo proceso histórico en varias etapas que abarcan desde la relativa a la expansión europea hasta la que denomina como de «las ciudades masificadas».

En la década siguiente, los principales autores latinoamericanos que contribuyeron con historias generales del urbanismo latinoamericano fueron los arquitectos Ramón Gutiérrez y Roberto Segre, que alternaron «la incipiente historiografía urbanística con la más consolidada periodización establecida a propósito de la arquitectura». ${ }^{39}$ Fuera de la región lo hicieron también otros como el ya referido Richard Morse, que tras estudiar Humanidades en la Universidad de Columbia se doctoró en 1952 con la tesis publicada en 1958 con el título From Comunity to Metropolis: a biography of São Paulo, estudio que — según el arquitecto argentino Alejandro Crispiani- abriría «el campo de la ciudad latinoamericana a un enfoque que posteriormente decantaría como "cultural"» en su propia obra. Profesionalmente Morse estuvo vinculado a la Universidad de Yale y, entre 1978 y 1984, a la Universidad de Stanford; la dirección del Programa sobre Estudios Latinoamericanos en la primera le permitiría diversificar sus contactos con diferentes especialistas latinoamericanos, entre ellos Jorge E. Hardoy. Su obra fue en parte traducida al español y al portugués durante las décadas de 1970 y 1980, teniendo una importante repercusión en los investigadores

36 Almandoz, 2011, 123.

37 Pradilla y Jiménez, 1973, 9.

38 Almandoz, 2011, 125.

1986.

39 Almandoz, 2003, 142. Al respecto consultar: Gutiérrez, 1983; Segre, Cárdenas y Aruca, 
interesados en el análisis del medio urbano latinoamericano. Parte de sus publicaciones se hicieron a través del Centro Latinoamericano de Ciencias Sociales (CLACSO), con el que estuvo vinculado. ${ }^{40}$ Por otro lado, desde Estados Unidos es importante destacar el aporte realizado también por profesoras estadounidenses como Susan Socolow y Louisa Hoberman, que recuperaron en esos momentos la fisonomía de las ciudades tardocoloniales como espacios sociales multiformes. ${ }^{41}$

Para el caso de España, una de las principales figuras de esos momentos fue la del historiador Francisco de Solano y Pérez-Lila, quien con el objetivo de paliar la escasa historiografía por entonces existente sobre la historia urbana de Hispanoamérica, promovió varias reuniones, cursos y empresas editoriales en las que se analizaba el fenómeno urbano, «convencido de que la ciudad era el fenómeno total que mezcla los más variados niveles de la realidad: social, económico, político y cultural». ${ }^{42}$ Junto a él destacan otros como el arquitecto Javier Aguilera Rojas, que con Luis Moreno Rexach publicó el libro titulado Urbanismo Español en América, resultado de la exposición organizada por el Ministerio de Vivienda y el Instituto de Cultura Hispánica en el Archivo General de Indias de Sevilla en 1973, con el objetivo de «mostrar la magnitud de la labor urbanística realizada por los españoles en América». ${ }^{43}$

De forma paralela a los estudios que analizan el pasado urbano desde una perspectiva continental, se fueron publicando también investigaciones

40 Crispiani, 2005. También a través del SIAP traduciría trabajos suyos originalmente publicados en inglés, como La investigación urbana latinoamericana: tendencias y planteos, donde destaca su interés como historiador «por la identificación de factores culturales e institucionales del pasado que influyen en el proceso social contemporáneo». Morse, 1971, 9.

41 Socolow y Hoberman, 1986.

42 En este sentido, Manuel Lucena afirma que Francisco de Solano desempeñó un papel de puente generacional, al permitir su «avance natural hacia los estudios de Historia Urbana» que su obra se consolide a lo largo de los años setenta como «referencia insustituible tanto por el americanismo tradicional como para el que mostraba visos de transformación» (Bernabéu Albert y Lucena Giraldo, 1997, 9-10 y 17). Solano tuvo varios cargos de responsabilidad en el CSIC, como el de director del Instituto Fernández Oviedo entre 1983 y 1984 y el de director del Centro de Estudios Históricos entre 1985 y 1991. Entre las publicaciones sobre historia urbana realizadas y coordinadas por él se encuentran: Estudios sobre la ciudad Iberoamericana (1975); Una hipótesis de trabajo sobre la investigación de la opinión pública en sociedades urbanas americanas (1981); Historia y futuro de la ciudad iberoamericana (Madrid, 1986); Ciudades hispanoamericanas y pueblos de indios (1990); «La expansión urbana ibérica por América y Asia: una consecuencia de los tratados de Tordesillas» (1996).

43 Aguilera Rojas y Moreno Rexach, 1973, 1. Javier Aguilera publicaría en los años posteriores otros trabajos con una visión regional sobre urbanismo colonial en la revista Ciudad y Territorio, entre los que se encuentran algunos como «Teoría urbanística en la colonización española de América. Las ordenanzas de nueva población» (1977) o «La cuadrícula: un modelo urbano para las ciudades americanas» (1982). 
con un enfoque local, regional o nacional, centradas en momentos cronológicos concretos. Los años setenta fueron especialmente importantes en este sentido, destacando la contribución realizada por institutos y centros de investigación que impulsaron estudios y la formación de recursos humanos en el análisis del pasado urbano latinoamericano. Entre ellos estuvo el único seminario interdisciplinario sobre historia urbana de México, creado en 1974 por un grupo de investigadores coordinado por la historiadora Alejandra Moreno Toscano, desde el que se dieron a conocer los primeros resultados de una investigación colectiva sobre la historia de la ciudad de México en el siglo XIX $;{ }^{44}$ o el Instituto Argentino de Investigaciones de Historia de la Arquitectura y del Urbanismo, creado en 1973 por los arquitectos Ramón Gutiérrez, Marina Waissman y Alberto Nicolini. ${ }^{45}$ Gutiérrez, además de dirigir junto a Dick Alexander la revista Documentos de Arquitectura Nacional y Americana, creada en 1973 en la Universidad Nacional del Nordeste, realizó algunos estudios en esos años, como los relativos a la Evolución urbanística y arquitectónica del Paraguay (1537-1911), publicados entre 1974 y 1977 en Corrientes por el Departamento de Historia de la Arquitectura de la Universidad Nacional del Nordeste, o Arquitectura del altiplano peruano, publicado por el mismo departamento en 1978.

Para el caso argentino destaca también en esos años el ya mencionado historiador José Luis Romero, quien junto a Luis Alberto Romero hizo una importante contribución a la historia urbana de la ciudad de Buenos Aires, al incluir una mirada más integradora de su desarrollo histórico en la obra titulada Buenos Aires. Historia de cuatro siglos, ${ }^{46}$ en unos momentos en los que se estaban produciendo a nivel nacional importantes cambios en las perspectivas de investigación, al fundarse una moderna y más profesional historia económica y social, con un tratamiento de las fuentes documentales más sofisticado y una valorización de los mercados regionales y locales como objeto principal de estudio. ${ }^{47}$ Otro ejemplo relevante, en este caso para Chile, tras los tempranos trabajos realizados por el historiador Tomás Thayer Ojeda sobre las ciudades chilenas durante el período de la

44 Miranda Pacheco, 2012, 353.

45 Arias, 1994, 29.

46 Romero y Romero, 1983.

47 González Lebrero, 2002, 10-11. En esos momentos, los aportes al estudio de Buenos Aires durante el período colonial se vieron también enriquecidos con trabajos como los realizados por Susan Socolow: The Merchants of Viceregal Buenos Aires: Family and Comerse, 1778-1810 (1978) y The Bureaucrats of Buenos Aires, 1769-1810: Amor al Real Servicio (1987). 
conquista, ${ }^{48}$ sería el arquitecto Gabriel Guarda, uno de los principales impulsores de la historia urbana de su país que, tras su Historia de Valdivia, 1552-1952 (1953), publicaría también La ciudad chilena en el siglo XVIII (1968) o la Historia urbana del Reino de Chile (1978). Estas publicaciones se verían complementadas con otras, como la realizada por Rodolfo Urbina y Santiago Lorenzo sobre La política de poblaciones en Chile durante el siglo XVIII (1978).

En Brasil se encuentran autores como el arquitecto Nestor Goulart Reis Filho, con diferentes trabajos sobre la historia del urbanismo colonial y contemporáneo, destacando entre sus publicaciones más tempranas algunas como Catálogo de Iconografia das Vilas e Cidades do Brasil Colonial, 1500-1720 (1964), o Evolução Urbana do Brasil: 1500-1720 (1968). En Colombia, Liliana Rueda Cáceres y William Plata Quezada mencionan, entre los autores pioneros para el estudio de la historia urbana de Bogotá, al arquitecto Carlos Martínez Jiménez, con la fundación de la revista Proa en 1946 y la publicación de sus libros Santafé de Bogotá (1968) y Bogotá; sinopsis sobre su evolución urbana 1536-1900 (1976), si bien consideran al historiador Germán Mejía Pavony, con su libro Los años del cambio. Historia urbana de Bogotá, 1820-1910 (1998), como el fundador de la historia urbana en Colombia. ${ }^{49}$

Desde España se hicieron también, durante las décadas de 1970 y 1980, importantes contribuciones a la historia urbana de Hispanoamérica, con estudios más específicos desde el punto de vista cronológico, geográfico y temático. Si vemos una de las principales publicaciones sobre historia de América por entonces existente, Revista de Indias — publicada en esos momentos por el entonces denominado Departamento de Historia de América «Fernández de Oviedo», perteneciente al Centro de Estudios Históricos del Consejo Superior de Investigaciones Científicas-, gracias a la revisión realizada por la historiadora Carmen Mena sabemos que entre 1940 y 1989 se publicaron en ella cincuenta y nueve artículos relativos a ciudades hispanoamericanas, correspondiendo la mayoría de ellos (concretamente treinta y uno) a números publicados durante los años setenta. También podemos observar que cincuenta y dos artículos se refieren al período colonial y únicamente siete al nacional, y que en los primeros las temáticas tratadas se

48 Thayer Ojeda, Tomás, Santiago durante el siglo XVI: Constitución de la propiedad urbana y noticias de sus primeros pobladores (1905) y Las Antiguas Ciudades de Chile. Apuntes históricos sobre su desarrollo y listas de los funcionarios que actuaron en ellas hasta el año 1565 (1911).

49 Rueda Cáceres y Plata Quesada, 2016, 63 y 64. 
refieren a cuestiones relacionadas con el régimen de abastecimiento ciudadano, la actividad higiénico-sanitaria, el arte, la cartografía, las fortificaciones, las instituciones, la población y el mestizaje, el proceso fundacional y el urbanismo. ${ }^{50}$

Otro centro vinculado al CSIC desde su creación, la Escuela de Estudios Hispano-Americanos de Sevilla, realizó también interesantes publicaciones en el sentido que venimos apuntando, no solo en su revista Anuario de Estudios Americanos sino también en formato libro, correspondiendo las primeras relativas a centros urbanos concretos a historiadores del arte. ${ }^{51}$ Las realizadas por historiadores son algo posteriores, de la década de 1980, y fueron el resultado de tesis de licenciatura y doctorado dirigidas por Luis Navarro García en el Departamento de Historia de América de la Universidad de Sevilla. ${ }^{52}$

Junto a estos trabajos, es preciso destacar también algunas recopilaciones sobre cartografía publicadas también por la Escuela de Estudios Hispano-Americanos (EEHA) en esas décadas, que continuaban la tarea iniciada por los autores anteriormente mencionados durante las primeras

50 Mena García, 1989. En dicho artículo, la autora destacaba el «crecimiento prodigioso» de los últimos años por el análisis del proceso urbano de Iberoamérica, si bien, el contexto histórico, a diferencia de la etapa contemporánea, estaba «relegado a un segundo plano y necesitado de nuevos y esclarecedores estudios que solo surgen a cuenta gotas, dada la dificultad que entraña la callada labor de archivo y el manejo de unas fuentes no siempre completas».

51 En este sentido se encuentran trabajos como los de Enrique Marco Dorta sobre Cartagena de Indias. La ciudad y sus monumentos (1951); Sidney David Markman sobre San Cristóbal de las Casas (1963); Jorge Bernales Ballesteros, Edificación de la Iglesia Catedral de Lima (1969) y Lima, la Ciudad y sus monumentos (1972); o María Antonia Durán Montero, Fundación de ciudades en el Perú durante el siglo XVI (1978). En el prólogo de este último (pág. XX), Bernales Ballesteros puso de relieve la necesidad que por entonces había de hacer investigaciones «sobre determinadas parcelas del viejo mundo hispano y circunscritos a un período dado», apuntando cómo «la historia del urbanismo hispano aun puede depararnos páginas de interesantes datos conservados en viejos archivos peninsulares y americanos».

52 Nos referimos, concretamente, a las de Carmen Mena García sobre Santa Marta durante la Guerra de Sucesión Española (1700-1713) (1982); María del Carmen Borrego Plá sobre Cartagena de Indias en el siglo XVI (1983), o María Luisa Laviana Cuetos sobre Guayaquil en el siglo XVIII. Recursos naturales y desarrollo económico (1987). En el prólogo de esta última obra (pág. XV), Luis Navarro explica los motivos que llevaron a la realización de estos estudios, entre los que menciona la poca atención que hasta esos momentos había merecido la historia de los núcleos urbanos indianos, «salvo en casos, como los de México y Lima en que, por exceso, se toma la historia de la capital, al menos en algunos aspectos, por la del país entero»; también afirmaba que «la constelación de ciudades, grandes y pequeñas, opulentas o indigentes, esparcidas por gran parte de América, solo brilla de ordinario por su ausencia en la historia de las Indias», a pesar de que «su estudio puede considerarse imprescindible para el conocimiento de la formación de la sociedad iberoamericana». Navarro García también dirigió la tesis doctoral de Santiago Lorenzo, que se publicaría en Chile con el título Origen de las ciudades chilenas. Las fundaciones del siglo XVIII (1986). 
décadas del siglo XX. Entre ellos se encuentran el realizado por José A. Calderón Quijano con Luis Navarro García titulado Biblioteca Nacional de París. Museo Británico. Public Record Office. Guía de Documentos, mapas y planos españoles y americanos (1962), o el del primero sobre Nueva Cartografía de Acapulco, Campeche y Veracruz (1969); también las series publicadas por Francisco Morales Padrón y José Llavador Mira sobre Mapas, planos y Dibujos sobre Venezuela existentes en el Archivo General de Indias, entre 1958 y 1965.

A ellos se sumarían otros como el de Fernando Chueca Goitia y Leopoldo Torres Balbás titulado Planos de ciudades iberoamericanas y filipinas existentes en el Archivo General de Indias, en cuya introducción se resalta como uno de sus objetivos el facilitar investigaciones y síntesis posteriores que permitan un mejor conocimiento de la «creación urbana» protagonizada por los españoles en América, que califica de casi inédita para esos momentos. Ambos autores consideran fundamental para el conocimiento del arte y la arquitectura hispanoamericana el trabajo de Diego Angulo sobre Planos de monumentos arquitectónicos de América y Filipinas en el Archivo General de Indias, publicado en los años treinta, del que este se considera paralelo y complementario, por representar para la historia del urbanismo lo que el primero supuso para la historia artística de América y Filipinas. ${ }^{53}$

La conmemoración del Quinto Centenario del llamado «Encuentro entre dos mundos», potenciaría el desarrollo de nuevos estudios generales sobre el urbanismo hispanoamericano. Uno de los principales trabajos en este sentido fue el dirigido por Francisco de Solano, titulado Historia Urbana de Iberoamérica, publicado en Madrid por el Consejo Superior de los Colegios de Arquitectos de España, la Comisión Nacional del Quinto Centenario y la Consejería de Obras Públicas y Transportes de la Junta de Andalucía entre 1987 y 1992, conformada por varios volúmenes: el primero dedicado a «la ciudad iberoamericana hasta 1573»; el segundo a la «ciudad barroca (1573-1750)»; el tercero y el cuarto a la «ciudad ilustrada».

Varias de las publicaciones de ese período fueron el resultado de encuentros académicos sobre historia urbana de América Latina que tuvieron lugar en los años previos a la conmemoración. ${ }^{54}$ De las obras colectivas

53 Chueca Goitia y Torres Balbás, 1981, VII y VIII.

54 Entre ellos se encuentran algunas como el «Seminario sobre la Ciudad Iberoamericana», celebrado en Argentina en 1985, del que derivaría una exposición itinerante y la edición del libro La ciudad hispanoamericana. El sueño de un orden, publicado en 1989 en Madrid (Almandoz, 2011, 133). 
que se publicaron en esos momentos sobre esta temática, Almandoz destaca también una de las obras compiladas por Francisco de Solano, la ya citada Historia y futuro de la ciudad iberoamericana (1986); la coordinada por Gabriel Alomar, De Teotihuacán a Brasilia (1987); Repensando la ciudad de América Latina (1988), compilada por Hardoy y Morse; o Construcción y administración de la ciudad latinoamericana (1990), de Nora Clichevsky. ${ }^{55}$ Especial mención merece también la colección «Ciudades de Iberoamérica», dirigida por Manuel Lucena Salmoral y publicada por la Fundación Mapfre América, conformada por volúmenes con temáticas específicas sobre el medio urbano de la región. ${ }^{56}$ Por otro lado, también en esos momentos aparecieron algunas publicaciones con las que se quiso hacer un balance de la investigación urbana en América Latina. ${ }^{57}$

Con posterioridad a esos años se produjo una fragmentación de los trabajos de historia urbana y urbanística, hecho que para el caso latinoamericano también se reflejó en la aparición de publicaciones específicas sobre determinadas ciudades o regiones y ámbitos cronológicos concretos. En este sentido, Almandoz destaca entre las nuevas modalidades historiográficas la historia cultural urbana, conformada a través de estudios de casos para períodos específicos de ciudades de la región, entre los que considera los de carácter histórico sobre imaginarios urbanos y formas de representación en las literaturas nacionales. ${ }^{58}$ Por otra parte, Sergio Miranda, tras referirse a algunas consideraciones realizadas por autoras como Annick

También, el «Simposio sobre la Urbanización en América desde sus orígenes hasta nuestros días», que tuvo lugar en Haití en 1986, cuyos resultados se plasmaron en la publicación que editaron Jorge Hardoy y Richard Morse titulada Nuevas perspectivas en los estudios sobre historia urbana (1989); o las «VII Jornadas de Andalucía y América», celebradas en la Universidad de La Rábida en 1987, de las que resultaría el libro de actas titulado La influencia andaluza en los núcleos urbanos americanos (1990). Para el caso de Brasil, destaca el primer «Seminario de Historia de la Ciudad y del Urbanismo» realizado en Bahía en 1990 bajo el auspicio de la Asociación Nacional de Postgrado e Investigación en Urbanismo (ANPUR), que continuaría desarrollándose en otras ciudades del país cada dos años. Almandoz, 2003, 132.

55 Almandoz, 2011, 132-133.

56 Entre ellos los dedicados a las Ciudades precolombinas, a la Fundación de ciudades hispanoamericanas, al Proceso de urbanización en América del Sur, o al Impacto de la urbanización en los centros históricos de Iberoamérica, este último realizado por Jorge E. Hardoy, Margarita Gutman y Sylvio Mutal. También con otros sobre el desarrollo histórico de diferentes ciudades de la región (como Río de Janeiro, Caracas, São Paulo, Lima, Quito...), cada uno de ellos realizado por grandes especialistas en las temáticas y espacios urbanos analizados.

57 En este sentido destacan obras como la editada por Fernando Carrión con la intención de hacer «un primer acercamiento» a esta temática «desde una perspectiva global y visualizada», con aportes que diferentes autores hacen sobre distintos países de la región (Carrión, 1989, i-ii). También artículos como el de González Reynoso, 2003.

58 Almandoz, 2003. 
Lemperiére y María Morales, concluye que para fines de la década de 1990 faltaba todavía un enfoque integrador dentro de la historia urbana de América Latina y, de forma más concreta, en la mexicana, sobre todo por la renuncia «a reflexionar sobre la ciudad como objeto y sujeto de la historia». ${ }^{59}$

\section{Artículos sobre ciudades publicados en la revista Anuario de Estudios Americanos}

Los artículos publicados en el Anuario de Estudios Americanos que tienen como objeto de análisis el medio urbano americano o determinados procesos históricos y/o artísticos desarrollados en ciudades y pueblos de la región, suman un total de ciento cincuenta y ocho trabajos, sin incluir las reseñas sobre libros con temáticas similares que aparecen en algunos de los números consultados. De ellos, apenas siete fueron publicados durante el período 1944-1949, doce en la década de 1950, dieciocho en la década de 1960, diecinueve en la de 1970, veintiuno en la de 1980, veinticinco en la de 1990, veinticinco también en la de 2000 y treinta y uno entre los años 2011 y junio de 2018. Por ello puede concluirse que su número ha ido incrementándose con el tiempo, aunque supone una proporción modesta en relación al volumen total publicado por la revista en cada una de las décadas. ${ }^{60}$

Del total de artículos sobre ciudades, la inmensa mayoría se refieren al período colonial, concretamente ciento veintisiete, al período prehispánico tres y al período nacional veinticinco, pudiéndose encontrar únicamente tres que abarcan un período cronológico que incluye tanto el colonial como el independiente. El predominio de los estudios relativos al período colonial no debe extrañarnos, dado el enfoque que ha tenido tradicionalmente la Escuela de Estudios Hispano-Americanos desde su creación, si bien es posible observar cómo en las últimas décadas se ha producido un incremento considerable de los trabajos relativos a los siglos XIX y XX, puesto que de los veinticinco que analizan procesos dentro de ese período, casi todos (veinte) fueron publicados entre los años 2001 y 2018. No obstante, los referidos al período colonial siguen siendo mayoría para esos años, con un total de treinta y tres.

59 Ver Miranda Pacheco, 2012, 357-360. Al respecto consultar Lempériere, 1999; Morales, Ros y Sánchez, 1998.

60 Nos referimos tanto a los artículos, como a los estudios y la sección «Varia» de los primeros números. (En las referencias a artículos del Anuario de Estudios Americanos se indicará volumen, año y páginas, omitiendo el nombre de la revista). 
En relación a los tres artículos publicados sobre asentamientos y centro urbanos prehispánicos, el primero es del antropólogo e historiador José Alcina Franch y se refiere a «Las ruinas de Palenque a la luz de los viajes de Guillermo Dupaix» (17, 1970, 109-124). Posteriormente, encontramos el de Ana Rita Valero de García Lascuráin sobre «Los indios de Tenochtitlan, la ciudad imperial Mexicana» (47, 1990, 29-63), y otro de Alcina Franch titulado «En torno al urbanismo precolombino de América. El marco teórico» (48, 1991, 3-47), en el que el autor analiza el proceso de urbanización prehispánico identificando las diferentes tipologías de los asentamientos, manejando para ello una bibliografía en la que se incluyen algunos de los autores ya mencionados por su contribución al desarrollo de la historia urbana americana. ${ }^{61}$

Los primeros estudios referidos al período colonial en los que lo urbano aparece de alguna manera significado, los encontramos en el tomo del año 1946. Concretamente, el realizado por Julia Herráez S. de Escariche sobre «Don Pedro Zapata de Mendoza, gobernador de Cartagena de Indias» $(3,1946,377-516)$, que incluye plantas de edificios de la ciudad, si bien se trata más bien de un estudio biográfico que sobre la propia ciudad de Cartagena. También el del historiador Guillermo Céspedes del Castillo sobre «Lima y Buenos Aires. Repercusiones económicas y políticas de la creación del virreinato del Plata» $(3,1946,677-874)$, que no podemos considerar dentro del campo de interés de la historia urbana propiamente por no conformar las ciudades de Lima y Buenos Aires el objeto principal de análisis y sí determinados procesos económicos y administrativos que son tratados para el conjunto del virreinato. En ese mismo número aparece el artículo de María Victoria González Mateos titulado «Marcos Ibáñez, arquitecto español en Guatemala» $(3,1946,877-910)$, que trata sobre la labor desempeñada por el que fuera arquitecto principal de la reconstrucción de la ciudad de Guatemala tras su destrucción por el terremoto del año 1773.

En los números siguientes de la revista podemos corroborar algo de lo expresado en el anterior apartado sobre el papel destacado que historiadores del arte e investigadores con intereses afines tuvieron a la hora de proveer el sustrato de la historia urbana hispanoamericana durante la primera mitad del siglo XX. En este sentido, encontramos artículos como el de Diego Angulo

61 Entre ellos se encuentran Jorge E. Hardoy (1964), Lewis Mumford (1961), o Richard P. Schaedel, de quien Alcina cita en reiteradas ocasiones su trabajo «On the definition of civilization, city and town in prehistoric America», presentado en el 37 Congreso Internacional de Americanistas (ICA), Mar del Plata, 1966. 
Íñiguez sobre «El gótico y el renacimiento en las Antillas (Arquitectura, Escultura, Pintura, Azulejos, Orfebrería» (4, 1947, 1-102). También, el del historiador colombiano Guillermo Hernández de Alba, preocupado por la preservación de los edificios coloniales de Bogotá tras los destrozos originados por el Bogotazo de $1948,{ }^{62}$ que ese mismo año publicó en la revista su artículo dedicado a «La iglesia de San Ignacio de Bogotá» (5, 1948, 507570); el de Francisco Xavier Mencos sobre «Arquitectos de la época colonial en Guatemala» (7, 1950, 163-209); y los de José de Mesa y Teresa Gisbert sobre «Noticias para la historia del Arte en Potosí» $(7,1950,471-503)$ y «Noticias para la historia del Arte en la Paz» $(10,1953,171-208){ }^{63}$

En el plano arquitectónico, y en consonancia con otras publicaciones del período comentadas en el anterior apartado, el Anuario publicó también algunos trabajos sobre fortificaciones realizados principalmente por historiadores. ${ }^{64}$ Asimismo, fueron importantes durante las primeras décadas de la revista, especialmente en los años sesenta y setenta, los trabajos sobre cartografía relativa a diferentes territorios americanos, en los que se incluían también mapas y planos sobre centros urbanos. ${ }^{65}$

62 Helguera, 1989, 747.

63 Otros artículos realizados por historiadores del arte o con temáticas relativas a ese campo de estudio publicados en la revista en años posteriores serían: Emilia Cobos Mancebo, «El convento de San Francisco de Santiago de Cuba en el siglo XVIII» (13, 1956, 105-123); Sidney David Markman, «San Cristóbal de las Casas» (19, 1962, 307-421, publicado al año siguiente en formato libro por la propia Escuela de Estudios Hispano-Americanos); Antonio Bonet Correa, «Las iglesias barrocas de Guatemala» (22, 1965, 705-765); Lino Gómez Canedo, «La iglesia de San Francisco en Santo Domingo (notas para la historia de su construcción)» (29, 1972, 61-78); Jorge Bernales Ballesteros, «Informes de los daños sufridos en la ciudad de Arequipa con el terremoto de 1784» (29, 1972, 295-314); Marta Fernández, «Las obras de Juan Serrano en la Universidad de México, 1642» (38, 1981, 479-497); María Antonia Triano Panadero, «Charcas: sociedad y arte» (39, 1982, 503-589); y María Antonia Durán Montero, «Lima en 1613. Aspectos urbanos» (49, 1992, 171-188).

64 Entre ellos se encuentran: Roberto Trigueros, «Las defensas estratégicas del río de San Juan de Nicaragua» (11, 1954, 413-513), con prólogo de José Antonio Calderón Quijano; Antonia M. Heredia Herrera, «Las fortificaciones de la isla Margarita en los siglos XVI, XVII y XVIII» (15, 1958, 429-514); Louis André Vigneras, «Fortificaciones de la Florida» (16, 1959, 533-552); Mariana Rodríguez del Valle, «El Castillo de San Felipe del Golfo Dulce. Historia de las fortificaciones de Guatemala en la Edad Moderna»(17, 1960, 1-103); Guillermo Lohmann Villena, «Las defensas militares de Lima y Callao hasta 1746» (20, 1963, 1-217); María Lourdes Díaz-Trechuelo Spínola, «Las defensas de Filipinas en el último cuarto del siglo XVIII» (21, 1964, 145-209); Víctor Fernández Cano, «Arquitectura militar de Cádiz en tiempos de los asaltos ingleses» (23, 1966, 623-646); Juan Manuel Zapatero, «Una traza inédita de ciudadela-castillo para la isla de San Juan de Ulúa» (23, 1966, 647-668); François-Auguste de Montequin, «El proceso de urbanización en San Agustín de la Florida, 1565-1821, arquitectura civil y militar» (37, 1980, 583-647); y Juan Manuel Zapatero, «El ingeniero militar de Cartagena de Indias don Antonio de Arévalo, 1742-1800» (38, 1981, 441-465).

65 En este sentido se encuentra el de Francisco Morales Padrón, Juana Gil Bermejo y María Teresa Garrido sobre «Cartografía de Puerto Rico en París, Londres y Madrid» (18, 1961, 615-649), siendo esta publicación un reflejo del interés del primero por impulsar los estudios sobre Puerto Rico en 
Otros grupos los conforman estudios sobre fundaciones de centros urbanos $^{66} \mathrm{y}$ los relativos al análisis de determinadas instituciones que tenían su sede en núcleos de población, principalmente los cabildos, aspecto este último que Carmen Delgado Viñas y Simon Gunn destacan como uno de los que han centrado un mayor interés en los trabajos sobre historia urbana. ${ }^{67}$ Las otras instituciones se refieren a otros escalones de la administración indiana como la Intendencia o el Consulado o a las de carácter religioso, principalmente cofradías, conventos, colegios y hospitales. ${ }^{68}$

la Edad Moderna (Calderón Quijano, 1987, CXXIV); también de Morales Padrón volvemos a encontrar el trabajo «Mapas, planos y Dibujos sobre Venezuela existentes en el Archivo General de Indias», que realizó con José Llavador Mira, tanto la primera serie (20, 1963, 533-618) como la segunda (21, 1964, 583-657); los de José Antonio Calderón Quijano sobre «Nueva cartografía de los puertos de Acapulco, Campeche y Veracruz en la edad moderna» $(25,1968,515-563)$ y «Cartografía de Belice y Yucatán» (32, 1975, 599-637); y el de Gabriel Guarda sobre «Los planos de la ciudad de San Marcos de Arica, siglos XVII-XVIII» $(37,1980,741-752)$.

66 Los artículos relativos a esta temática son: Manuel Luengo Muñoz, «Noticias sobre la fundación de la ciudad de Nuestra Señora de Santa María de los Remedios del cabo de la Vela» (6, 1949, 755-798); Eugenio Sarrablo Aguareles, «La fundación de Jaruco en Cuba y los primeros condes de ese título» (8, 1951, 443-501); Jorge Comadrán Ruiz, «Nacimiento y desarrollo de los núcleos urbanos y del poblamiento de la campaña del país de Cuyo durante la época hispana (1551-1810)» (19, 1962, 145-246); Rafael Eladio Velázquez, «La fundación de la Villeta del Guarnipitán en 1714 y la población de litoral paraguayo» (21, 1964, 211-246); Florencio Fajardo Terán, «El proceso colonizador en el Río de la Plata. Pérez del Puerto y los orígenes de Rocha» (31, 1974, 269-322); Carmen Mena García, «El traslado de la ciudad de nombre de Dios a Portobelo a fines del siglo XVI» (40, 1983, 71-102); o, en fecha más reciente, el artículo de Alain Musset sobre «Los traslados de ciudades en América: autorretrato de una sociedad en crisis» (62-2, 2005, 77-102).

67 En esta línea, dentro de la revista encontramos ejemplos como: Ramón Ezquerra Abadía, «Un presupuesto americano: el del cabildo de Nueva Orleans al terminar la soberanía española» (5, 1948, 675-702); Joaquín E. Ruiz Alemán, «Los municipios cubanos en el bienio constitucional» (29, 1972, 379-387); Luis Navarro García, «El privilegio de los regidores en el abasto de Cartagena de Indias» (38, 1981, 173-214); María Luisa Laviana Cuetos, «Las ordenanzas municipales de Guayaquil, 1590» (40, 1983, 39-69); Pilar Sanchiz Ochoa, «Poder y conflictos de autoridad en Santiago de Guatemala durante el siglo XVI» (49, 1992, 21-54); Héctor Ramón Lobos, «Los cabildos y la dinámica revolucionaria en el Río de la Plata. Un esfuerzo de comprensión a partir del caso cordobés» (46, 1989, 383-407); Antonio Gómez Vizuete, «Los primeros ayuntamientos liberales en Puerto Rico (1812-1814 y 1820-1823)» (47, 1990, 581-615); Frédérique Langue, «Antagonismos y solidaridades en un cabildo colonial. Caracas, 1750-1810» (49, 1992, 371-393); Ángeles Hijano Pérez, «El régimen municipal de la isla de Cuba en la segunda mitad del siglo XIX» (50-2, 1993, 243-278); José Luis Caño Ortigosa, «Mineros en el Cabildo de la villa de Guanajuato: 1660-1741»(63-1, 2006, 187-209); y Claudina Paulina Machuca Chávez, «Cabildo, negociación y vino de cocos: el caso de la villa de Colima en el siglo XVII» (66-1, 2009, 173-192)

68 Es este el caso de: Carmen Castañeda, «Los intendentes en el gobierno de Guadalajara, 1790-1809» (59-1, 2002, 67-80); Julia Herráez y Sánchez de Escariche, «Dos cofradías del Corazón de Jesús en Lima» (9, 1952, 389-413); Juan Bautista Olaechea Labayen, «El colegio de San Juan de Letras de Méjico» (29, 1972, 585-596); María Justina Sarabia Viejo, «Notas sobre el Hospital del Amor de Dios de México en el siglo XVI» (30, 1973, 295-316); María Paulina Molino García, «La sede vacante en Cartagena de Indias, 1534-1700» (32, 1975, 1-23), referido al obispado; María Isabel Paredes Vera, «San Nicolás de Bari, en La Española, primer hospital de América» (33, 1976, 933-948); Jesús Paniagua 
El análisis del medio urbano americano a través de la historia social aparece también reflejado en una serie de artículos publicados por la revista. Entre ellos destaca de forma especial el de Inge Langenberg sobre «Urbanización y cambio social. El traslado de la ciudad de Guatemala y sus consecuencias para la población y sociedad urbana al fin de la época colonial (1773-1824)» $(36,1979,351-374)$, por incluir aspectos relativos tanto a la estructura espacial como demográfica, profesional y social, al tiempo que cita a gran parte de los autores que en esos momentos eran un referente para el estudio del urbanismo latinoamericano, como Schaedel, Morse, Hardoy, Solano y Socolow, entre otros.

Con un enfoque social podemos encontrar también otros trabajos que incluyen aspectos demográficos, como los del historiador Pablo Tornero Tinajero sobre «Estudio de la población de Pensacola (1784-1820)» $(34,1977,537-561)$ y «Sociedad y población en San Agustín de la Florida (1786)» $(35,1978,233-260)$, o el de la historiadora venezolana Lila Mago de Chópite sobre «La población de Caracas (1754-1820). Estructura y características» (54-2, 1997, 511-541). También los que se interesan por el estudio de un determinado conflicto en un centro urbano durante un momento concreto ${ }^{69}$ y los que analizan las características de una sociedad urbana en su conjunto, como hace la historiadora Manuela Cristina García Bernal en «Apuntes sobre la sociedad urbana de Yucatán en el siglo XVI» (40, 1983, 3-38), o el historiador francés Jacques P. Simard en «Formación,

Pérez, «Cofradías limeñas: San Eloy y la Misericordia (1597-1733)» (52-1, 1995, 13-35); Ángel Álvarez Romero, «El Consulado en el proceso de independencia de Cartagena de Indias» (53-2, 1996, 97-121), y David Carbajal López, «"Servicio de Dios, beneficio del público y utilidad del Estado”. La fundación de conventos franciscanos en la Nueva España, 1700-1821» (69-2, 2012, 665-693).

69 En este sentido se encuentran los trabajos de Eugenio Sarrablo Aguareles, «Una conmoción popular en el México virreinal del siglo XVIII» (7, 1950, 125-161), en el que analiza un motín sucedido en la ciudad de Puebla de los Ángeles; Demetrio Ramos Pérez, «Alzaga, Liniers y Elio en el Motín de Buenos Aires del primero de enero de 1809» (21, 1964, 489-580); José Luis Mora Mérida, «Comportamiento político del clero secular de Cartagena de Indias en la preindependencia» (35, 1978, 211-231); Julián B. Ruiz Rivera, «Potosí, tensiones en un emporio minero» (40, 1983, 103-137); José Óscar Frigerio, «La rebelión criolla de la Villa de Oruro. Principales causas y perspectivas» (52-1, 1995, 57-90); Jurgi Kintana Goiriena, «La "nación vascongada" y sus luchas en el Potosí del siglo XVII. Fuentes de estudio y estado de la cuestión» (59-1, 2002, 287-310); o Wilson González Demuro, «Iglesia y crisis monárquica en el Río de la Plata al finalizar la época colonial. Un caso: Montevideo y su cura vicario, Juan José Ortiz (1783-1815)» (62-1, 2005, 161-180). Dentro de este apartado podemos incluir también estudios más recientes, como el de Inés Quintero sobre «Los nobles de Carcas y la Independencia de Venezuela» (64-2, 2007, 209-232); Sigfrido Vázquez Cienfuegos y Juan Bosco Amores Carredano, «En Legítima Representación: los firmantes del fallido proyecto de Junta de La Habana en 1808» (68-1, 2011, 105-139); Hugo Contreras Cruces, «Aucas en la ciudad de Santiago. La rebelión mapuche de 1723 y el miedo al "oro en Chile central» (70-1, 2013, 67-98); o Manuel Pareja Ortiz, «El "pueblo" bogotano en la revolución del 20 de julio de 1810» (71-1, 2014, 281-311). 
desarrollo y configuración socio-étnica de una ciudad colonial: Cuenca, siglos XVI-XVIII» (54-2, 1997, 413-445). Otros, en cambio, se centran en el análisis de determinados colectivos sociales urbanos. ${ }^{70}$

También hay artículos con un enfoque entre lo social y lo económico, como el realizado por Mercedes Gantes Tréllez sobre «Aspectos socio-económicos de Puebla de Los Ángeles (1624-1650)» (40, 1983, 497-613), o el de Ana María Martínez de Sánchez, «Infraestructura del abasto de carne a la ciudad de Córdoba: los Corrales (1783-1810)» (50-2, 1993, 129-162); otros con perspectiva predominantemente económica, como sucede con los de José Joaquín Real Díaz, «Las Ferias de Jalapa» (16, 1959, 167-314); James A. Lewis, «Nueva España y los esfuerzos para abastecer La Habana. 1779-1783» (33, 1976, 501-526); y Emanoel Soares da Veiga García, «Buenos Aires en la coyuntura borbónica» $(35,1978,197-210)$, en el que analiza la situación de la ciudad rioplatense en el marco de las reformas económicas aplicadas por los Borbones durante el siglo XVIII. ${ }^{71}$

70 Es lo que sucede con artículos como: Vicenta Cortés Alonso, «Los esclavos domésticos en América» (24, 1967, 955-983), en el que analiza el caso de la ciudad de Tunja; Hernán Asdrúbal Silva, «Pulperías, tendejones, sastres y zapateros. Buenos Aires en la primera mitad del siglo XVIII» (26, 1969, 471-506); Carmen Gómez Pérez, «Los extranjeros en la América colonial: su expulsión de Cartagena de Indias en 1750» (37, 1980, 279-311); Manuel Lucena Salmoral, «Los comerciantes caraqueños y sus diversas categorías: comerciantes, mercaderes, bodegueros y pulperos» (39, 1982, 252-273); Jorge Daniel Gelman, «Economía natural - Economía monetaria (los grupos dirigentes de Buenos Aires a principios del siglo XVII)» (44, 1987, 89-107); Fernando Iwasaki, «Vidas de santos y santas vidas: hagiografías reales e imaginarias en Lima colonial» (51-1, 1994, 47-64); Clara López Beltrán, «Intereses y pasiones de los vecinos de La Paz en el siglo XVII. La élite provinciana en Charcas, virreinato del Perú» (52-1, 1995, 37-56); Christian Büschges, «Linaje, patrimonio y prestigio. La nobleza titulada de la ciudad de Quito en el siglo XVIII» (56-1, 1999, 123-145); Miguel A. Rosal, «Negros y pardos propietarios de bienes raíces y de esclavos en el Buenos Aires de fines del período hispánico» (58-2, 2001, 495-512); Antonio Rubial García, «Las santitas del barrio. "Beatas” laicas y religiosidad cotidiana en la ciudad de México en el siglo XVII» (59-1, 2002, 13-37); Jacqueline Vasallo, «Delincuentes y pecadoras en la Córdoba tardo colonial» (6-2, 2006, 97-116); Luis Martínez Ferrer, «La preocupación médica y religiosa del doctor Pedro López por las personas de raza negra de la ciudad de México (1582-1597)» (65-2, 2008, 71-89); o Patricio Hidalgo Nuchera, «Los "malos usos" y la reglamentación de los temascales públicos mexicanos (1686-1691)» (69-1, 2012, 91-108). Junto a estos trabajos, nos encontramos otros artículos centrados también en una ciudad y su región para un período cronológico específico, con una perspectiva general que no incluye solo aspectos sociales, como sucede con: Florencio Fajardo Terán, «Banda Oriental del Río de la Plata: un español ilustre y una ciudad señera» (19, 1962, 423-499), en el que hace un estudio de la población de San Fernando de Maldonado durante la gestión de Rafael Pérez del Puerto; Ramón María Serrera Contreras, «La ciudad de Santiago de Querétaro a finales del siglo XVIII: apuntes para su historia urbana» (30, 1973, 489-555); Carmen Mena García, «Santa Marta durante la Guerra de Sucesión española» (36, 1979, 569-702); o Manuel Lucena Salmoral, «La ciudad de Quito hacia el mil ochocientos» (51-1, 1994, 143-164).

71 También los artículos de Francisco Castillo Meléndez, «La Hacienda Municipal Indiana: el caso de La Habana y Santiago de Cuba hasta 1700» (42, 1985, 501-547); Teodoro Hampe Martínez, «Actividad mercantil del puerto de Lima en la primera mitad del siglo XVI» (42, 1985, 549-571); Arturo Ariel Betancur, «La provisión de servicios en el puerto colonial de Montevideo: Alcances y 
Son escasos, en cambio, para el período analizado, los artículos que ponen su énfasis en aspectos culturales, pudiéndose encontrar dos relativos a fiestas en el volumen del año 1987: Alfonso García Morales, «Las fiestas de Lima (1632), de Rodrigo de Carvajal y Robles» (44, 1987, 141-171), y Juan Pedro Viqueira, «Diversiones públicas y cultura popular en la ciudad de México durante el siglo de las luces» (44, 1987, 195-228). También en el volumen de 1992, concretamente: María Jesús Mejías Álvarez, «Muerte regia en cuatro ciudades peruanas del barroco» $(49,1992,109-205)$, y Fernando Iwasaki Cauti, «Toros y sociedad en Lima colonial» (49, 1992, 311-333) Más recientes son el de María Luisa Domínguez Guerrero sobre «El poder del rey ausente: la proclamación de Felipe II en Cuzco en 1557» (72-2, 2015, 605-629) y el de Escardiel González Estévez y Olaya Sanfuentes Echevarría titulado «Los toros en Santiago de Chile durante el período colonial» (74-1, 2017, 127-154).

Otros artículos relacionados con la cultura, pero no con las fiestas, son el de Carlos Alberto González Sánchez titulado «Consideraciones sobre el comercio de libros en Lima a principios del siglo XVII» (54-2, 1997, 665-692), y el de Salvador Bernabéu Albert titulado «Pedro José Velarde: un rapsoda callejero en el México del siglo XVIII» (62-2, 2005, 187-218). Relacionados con el tema de las identidades, encontramos dos artículos: Adriana Delfina Rocher Salas, «Religiosidad e identidad en San Francisco de Campeche. Siglos XVI y XVII» (63-2, 2006, 27-47), y Gleydi Sullón Barreto, «De integración e identidades» (75-1, 2018, 97-126).

Hay también estudios que analizan las consecuencias de un desastre en algún centro urbano de la región, principalmente terremotos o epidemias. En este sentido se encuentran, junto a los ya mencionados de María Victoria González Mateos, Jorge Bernales Ballesteros e Inge Langenberg, los siguientes: Jorge Luján Muñoz y María Cristina Zilbermann de Luján, «Santiago de Guatemala en vísperas de los terremotos de 1773» (32, 1975, 541-571); Miguel Ángel Cuenya, «Peste en una ciudad novohispana. El matlazahualt de 1737 en la Puebla de los Ángeles» (53-2, 1996, 51-70); Charles Walker y Ricardo Ramírez Castañeda, «Cuentas y cultura material: la reconstrucción del Real Palacio de Lima después del terremoto de 1746»

\footnotetext{
limitaciones de una fuente local de riqueza» (53-2, 1996, 123-145); Marcos D. Arriaga Mesa, «Un acercamiento al comportamiento del precio de los esclavos en La Habana en la segunda mitad del siglo XVI» (56-1, 1999, 15-40); Guillermina del Valle Pavón, «Bases del poder de los mercaderes de plata de la ciudad de México. Redes, control del Consulado y de la Casa de Moneda a fines del siglo XVII» (68- 2, 2011, 565-598); y Luisa Consuelo Soler Lizarazo, «Cosecheros-huerteros: bajo la sombra de los monopolios cacaoteros del Guayaquil colonial» (72-2, 2014, 603-629).
} 
(59-2, 2002, 657-696); y Alfredo Palacios Roa, «Dominio y catástrofe. Los terremotos en Concepción, Chile: 1550-1751» (69-2, 2012, 569-600).

Un aspecto importante para los trabajos relativos al período colonial es la aparición en los últimos años de estudios que adoptan una visión multidisciplinar a la hora de tratar algún aspecto relacionado con el medio urbano hispanoamericano. Un ejemplo en este sentido lo constituye el dossier del que soy coordinador, titulado «Las alamedas: espacios para la socialización en las urbes españolas e hispanoamericanas», en el que participan tanto historiadores del arte como especialistas en Historia Moderna e Historia de América, tratando aspectos relativos tanto a la conformación y evaluación del paisajes urbanos y arquitectónicos de esos espacios urbanos, como a los usos cotidianos y sociales que tuvieron ${ }^{72}$. Con ello se ha contribuido, en parte, a recuperar la presencia de estudios realizados por historiadores del arte en la revista, que desde los años ochenta se había visto muy mermada, contribuyendo a esto último también la publicación de otros trabajos como los ya mencionados de María Jesús Mejías, Escardiel González y Olaya Sanfuentes, o el de Pedro Luengo Gutiérrez sobre «Mestizaje y globalización en la arquitectura de Filipinas. Obando y Los Baños, dos casos de iglesias franciscanas de la segunda mitad del siglo XVIII» (71-1, 2014, 227-252).

En cuanto a la visión multidisciplinar, en la que el análisis histórico se completa con aportes de otras áreas de conocimiento, destacan también ejemplos como el artículo de Juan Alberto Molina García (licenciado en Ciencias Exactas y en Filosofía y Letras) sobre «Aspectos climatológicos en las obras de funcionarios reales e ingenieros militares del siglo XVIII hispanoamericano» (71-1, 2014, 253-279), o el de la economista italiana Angela Orlandi sobre «Ciudades y aldeas del Nuevo Mundo en los documentos de los mercaderes y viajeros italianos del Quinientos» $(73-1,2016,45-64){ }^{73}$

Sobre los artículos publicados que se refieren al período nacional hay que esperar a 1980 para encontrarnos el primero: el que Pablo Emilio

72 Los artículos que integran el dossier son: Antonio Albardonedo Freire, «La alameda, un jardín público de árboles y agua. Origen y evolución del concepto»; Manuel Fernández Chaves, «Las alamedas en la España Moderna. Interpretación histórica de un espacio urbano»; Emilio José Luque Azcona, «Conformación y características de las alamedas y paseos en ciudades de Hispanoamérica»; Álvaro Recio Mir, «Alamedas, paseos y carruajes: función y significación social en España y América (siglos XVI-XIX)» y Clara Bejarano Pellicer, «Música y alameda en la Edad Moderna: el caso de la sevillana alameda de Hércules en el siglo XVIII» (72-2, 2015, 415-576).

73 Hay otros dos artículos relativos al período colonial que fueron publicados en la revista, pero no entran dentro de ninguna de las temáticas mencionadas hasta el momento: Mario Góngora, «Sondeos en la antroponimia colonial de Santiago de Chile» (24, 1967, 1324-1355) y María Lourdes Díaz-Trechuelo Spínola, «Antonio Fernández de Roxas y su "Topographia de la ciudad de Manila"» $(15,1958,225-271)$. 
Pérez-Mallaína Bueno publica sobre «Profesiones y oficios en la Lima de 1850» (37, 1980, 191-233), que más que un estudio de la ciudad en sí misma lo es de las profesiones y oficios que existían en la capital peruana a mediados del siglo XIX. En el mismo volumen de la revista se publica un artículo de Ramón Gutiérrez, junto a Idilio Santillana, Graciela M. Viñuales y Amaya Irarrázabal, sobre «Coporaque, la trayectoria de un poblado andino» $(37,1980,565-581)$, en el que se hace tanto una evolución histórica de la zona como de su planta urbanística, de la plaza, el templo y el beaterio. El siguiente no aparece hasta dieciséis años después, el realizado por Ana María Mateu que lleva por título «Poder y relaciones políticas y económicas en Mendoza, Argentina 1880-1920» (53, 1996, 199-226), en el que la ciudad vuelve a aparecer como un mero escenario para el análisis de aspectos de tipo político y económico.

El primero de los artículos que sobre el período nacional incluye en su objeto de estudio aspectos relacionados tanto con la economía, la sociedad y la estructura urbana, es el de Elda E. González Martínez titulado «Café, inmigración y estructura urbana: São Paulo en el siglo XIX y principios del XX» (54-2, 1997, 593-611). El siguiente, el de Miguel A. Rosal sobre «La exportación de cueros, lanas y tasajo a través del puerto de Buenos Aires entre 1835 y 1854» $(55-2,1998,565-588)$, se centra en aspectos relacionados con el comercio de exportación a través del puerto de Buenos Aires, por lo que podemos incluirlo como un ejemplo más de estudios en los que la ciudad aparece como un mero marco espacial seleccionado para profundizar en el conocimiento de determinados procesos históricos.

Como ya se ha mencionado, el número de trabajos sobre el período nacional se incrementa de manera considerable durante las dos últimas décadas, siendo las temáticas menos diversas que las expuestas para el período colonial. En contraste con lo que hemos mencionado para dicho período, para este grupo hay un mayor enfoque en aspectos culturales. ${ }^{74}$

74 En este sentido encontramos artículos como: José Antonio Vidal Rodríguez, «La reconstrucción de la identidad gallega en Cuba: procesiones, festivales y romerías regionales en La Habana (1804-1920)»(59-2, 2002, 511-540); Leandro Losada, «La alta sociedad, el mundo de la cultura y la modernización en la Buenos Aires del cambio del siglo XIX al XX» (63-2, 2006, 171-193); José María Aguilera Manzano sobre «Publicaciones periódicas e imprentas de La Habana entre 1824 y 1845 en los archivos cubanos y españoles» (64-1, 2007, 293-328); Lea Geler, «Guardianes del progreso. Los periódicos afroporteños entre 1873 y 1882» (65-1, 2008, 199-226); Rodrigo Andrés Pérez Lisicic, «Los inicios de la enseñanza del Derecho Constitucional en el Chile decimonónico: el Liceo de Chile y el Colegio de Santiago (1828-1831)» (68-1, 2011, 141-162); o Pablo Ortemberg, «Geopolítica de los monumentos: los próceres en los centenarios de Argentina, Chile y Perú (1910-1924)» (72-1, 2015, 321-350). También: Mauricio F. Rojas Gómez y Marco A. León León, «Control social y construcción 
Otras de las temáticas que aparecen tratadas con mayor frecuencia se refieren a cuestiones medioambientales, destacando en este sentido algunos trabajos sobre la gestión de recursos hídricos, como el artículo de Inmaculada Simón Ruiz sobre «Centralización o descentralización: gestión pública o privada de un "bien escaso": historiografía sobre el agua en la ciudad de México en los siglos XIX y XX» (64-2, 2007, 233-252), o el de Carlos O. Crespo Flores sobre «Privatización del agua y racismo ambiental en ciudades segregadas. La empresa Aguas del Illimani en las ciudades de La Paz y El Alto (1997-2005)» (66-2, 2009, 105-122). Relacionados con este asunto, pero desde el punto de vista de la higiene urbana, se encuentran los artículos de Cecilia Moreyra sobre «Cultura material e higiene cotidiana en la Córdoba del Ochocientos» (74-1, 2017, 211-234), y el de Inmaculada Simón Ruiz y Raúl Sánchez Andaur sobre «Introducción al paradigma higiénico sanitario en Chile (1870-1925): discursos y prácticas» (74-2, 2017, 643-674).

Los que cuentan con un enfoque de la historia social, muy numerosos para el período colonial, están aquí escasamente representados, pudiéndose encontrar en este sentido los que se centran en el estudio de un determinado colectivo urbano, como los artículos de Emma Teresita Raspi, «El mundo artesanal de dos ciudades del norte argentino. Salta y Jujuy, primera mitad del siglo XIX» (58-1, 2001, 161-183); Laura Giraudo, «De la ciudad "mestiza” al campo "indígena": internados indígenas en el México posrevolucionario y en Bolivia» (67-2, 2010, 519-547); o Alejandra Palafox Menegazzi, «Sodomía y masculinidad en la ciudad de México (1821-1870)» (72-1, 2015, 289-320).

También están poco representados los que podemos enmarcar dentro de la historia política, como sucede con los artículos de Fabián Herrero, «Buenos Aires en tiempo de Revolución. Centralización y confederación americana» (67-2, 2010, 663-678); Leandro Lichtmajer y Florencia Guzmán, «Hacer política en un pueblo azucarero: prácticas a ras del suelo en la transición del radicalismo al peronismo. Bella Vista (Argentina)» (74-1, 2017, 295-321); e Inés Rojkind, «"La revolución está vencida, pero el gobierno está muerto". Crisis política, discursos periodísticos y demostraciones callejeras en Buenos Aires, 1890» (74-1, 2017, 295-321).

Llama la atención lo poco tratados que están otros temas que para el período colonial sí cuentan con una destacada presencia. Nos referimos,

de hegemonía en la ciudad de Concepción (Chile), 1860-1900» (70-2, 2013, 641-671), artículo en el que sus autores analizan algunas transformaciones culturales experimentadas por sectores subalternos de dicha localidad, en concreto en lo que se refiere a aspectos relativos a la evolución y valoración de las ideas de trabajo y educación. 
por ejemplo, a trabajos relativos al poder local, pudiéndose encontrar únicamente el de María Dolores Palomo Infante sobre «Los Ayuntamientos de los pueblos indígenas de Chiapas en el siglo XIX y su relación con los asuntos de justicia» (66-1, 2009, 21-46); o también al urbanismo contemporáneo latinoamericano, representado por un trabajo de mi autoría sobre «Globalización y ciudad: la reinvención de espacios urbanos en América Latina» (65-2, 2008, 265-287), en la línea de los estudios interesados en el análisis de la dimensión global de las ciudades bajo el enfoque de la competencia y la competitividad, y el artículo de Juan Sebastián Malecki sobre «Ernesto La Padula en Córdoba, peronismo y ciudad 1946-1955» (75-1, $2018,323-352) .^{75}$

\section{Reflexiones finales}

La presencia de trabajos sobre historia urbana publicados por el Anuario de Estudios Americanos desde su aparición en 1944 hasta junio de 2018, es poco significativa si la comparamos con los estudios en los que la ciudad aparece, más que como un objeto de análisis en sí misma, como un mero escenario para la comprensión de determinados procesos históricos. Si tenemos en cuenta que hasta los años setenta fueron geógrafos, arquitectos e historiadores del arte los principales impulsores de los estudios sobre historia urbana, y que la presencia de los dos primeros fue poco significativa en la revista frente a la de historiadores, podremos entender fácilmente el motivo de lo expuesto. $\mathrm{El}$ aporte inicial realizado por los historiadores del arte para el conocimiento del desarrollo urbano y arquitectónico de la región sí ha quedado, en cambio, claramente reflejado. También el de los historiadores a partir de fines de la década de 1970, pudiéndose diferenciar entre ellos un importante número de académicos españoles, latinoamericanos de diferentes países de la región y, en menor medida, de otros europeos como alemanes o franceses.

En relación a las temáticas que contemplan los trabajos en los que lo urbano aparece destacado de alguna manera, son diferentes para los períodos colonial y nacional.

75 Por último, mencionar que únicamente tres artículos comprenden un marco cronológico que incluye tanto el período colonial como el independiente. Nos referimos a los trabajos de David Carbajal sobre «Un obispado para Veracruz, 1799-1846. Del honor de la ciudad a la lealtad al Estado» (62-1, 2005, 181-208) y «Pública utilidad o causa pública: la utilidad de los conventos de la provincia de Veracruz, 1786-1834» (65-2, 2008, 151-175). También el de Francisco Bolsi titulado «Familia, estrategias de reproducción social y comercio de exportación en Tucumán, Argentina, 1780-1820. Una aproximación a partir de la familia Posse» (70-1, 2013, 129-156). 
Para el primero se encuentran principalmente los relacionados con los poderes y las instituciones de gobierno local, la cartografía, las fortificaciones, los procesos fundacionales de ciudades y los que analizan algún conflicto o se centran en un determinado colectivo urbano, siendo llamativa la escasa presencia de artículos sobre grupos urbanos considerados como «subordinados», a pesar del interés que la historia urbana les prestó durante los años ochenta. En cambio, están escasamente representados los temas relativos a la historia política, económica y, principalmente, cultural. También estudios de tipo transatlántico en los que se establezcan comparaciones sobre las formas de desarrollo de centros urbanos y la circulación de ideas y modelos urbanísticos, que tanto interés despertaron en los años ochenta. Para el período nacional destacan, sin embargo, los que se refieren a aspectos culturales.

Por último, cabe subrayar el hecho de que la práctica totalidad de los artículos publicados por el Anuario de Estudios Americanos que se refieren a ciudades o que utilizan un medio urbano determinado como escenario para el análisis de procesos históricos concretos, aplican un marco local o regional de análisis. En este sentido, estos trabajos suponen un importante aporte para el conocimiento de la historia urbana de la región, en unos momentos en los que la comparación de casos concretos permite obtener resultados que pueden corroborar, o no, algunas de las hipótesis planteadas por estudios de carácter más genérico.

Recibido el 22 de febrero de 2018 Segunda versión el 9 de julio de 2018

Aceptado el 8 de agosto de 2018

\section{Referencias bibliográficas}

Aguilera Rojas, Javier y Moreno Rexach, Luis J., Urbanismo Español en América, Exposición celebrada en el Archivo General de Indias, Sevilla, Madrid, Editora Nacional, 1973.

Almandoz, Arturo, «Historiografía urbana en Latinoamérica: del positivismo al postmodernismo», Diálogos, 7 (1), Maringá, 2003, 117-156. http://www.uem.br/dialogos/ index.php?journal $=$ ojs\&page $=$ article $\& o p=$ viewArticle $\&$ path $\% 5 B \% 5 \mathrm{D}=214$ [Consultado: 17/11/2017].

Almandoz, Arturo, Entre libros de historia urbana. Para una historiografía de la ciudad y el urbanismo en América Latina, Caracas, Equinoccio, Universidad Simón Bolívar, 2008. 
Almandoz, Arturo, «De los planos de Indias a las monografías del Quinto Centenario: la influencia española en la historiografía urbana latinoamericana, 19201992», en Guiance, Ariel (dir.), La influencia de la historiografía española en la producción americana, Madrid, Marcial Pons Ediciones de Historia, 2011, 115-134.

Arias, María de las Nieves, «Reflexiones acerca de la revitalización de centros históricos en la Argentina», en Rehabilitación integral en áreas o sitios históricos latinoamericanos. Memorias del Seminario-Taller 10-14 de enero de 1994, Quito, Ediciones Abya-Yala, ORCALC, 1994, 27-38.

Bernabéu Albert, Salvador y Lucena Giraldo, Manuel, «Recordando a Francisco de Solano», Revista de Indias, 209, Madrid, 1997, 7-19.

Bonet Correa, Antonio (ed.), Urbanismo e historia urbana en España: primer simposio, Revista de la Universidad Complutense, 115, Madrid, 1979.

Bonet Correa, Antonio (coord.), Urbanismo e historia urbana en el mundo hispano: segundo simposio, 1982, Madrid, Universidad Complutense, 1985.

Calderón Quijano, José Antonio, El americanismo en Sevilla, 1900-1980, Sevilla, Escuela de Estudios Hispano-Americanos, 1987.

Camacho, Luis Eduardo, «Sociedad Interamericana de Planificación, SIAP. 50 años. Vida institucional y programática», Bitácora Urbano Territorial, 11, 1, Bogotá, 2007, 268-284. http://www.redalyc.org/articulo.oa?id=74811117 [Consultado: 8/05/2017].

Capel, Horacio, La morfología de las ciudades (I. Sociedad, cultura y paisaje urbano), Barcelona, Ediciones del Serbal, 2002.

Capel, Horacio, «La historia, la ciudad y el futuro», Scripta Nova. Revista Electrónica de Geografía y Ciencias Sociales, XIII, 307, Barcelona, 2009, http:// www.ub.es/geocrit/sn/sn-307.htm [Consultado: 3/04/2017].

Capel, Horacio y Tatjer, Mercedes, «El Profesor Antonio Bonet Correa y la historia del urbanismo en España», Ciudad y Territorio, 94, Madrid, 1992, 7-13.

Carrrión, Fernando (ed.), La investigación urbana en América Latina. Caminos recorridos y por recorrer. Estudios Nacionales, Quito, CIUDAD, 1989-1990.

Castillo Fernández, Simón, «Reseña de Entre libros de historia urbana. Para una historiografía de la ciudad y el urbanismo en América Latina», EURE, 35, 106, Santiago de Chile, 2009, 171-176, http://www.scielo.cl/scielo.php?script =sci_arttext\&pid=S0250-71612009000300009 [Consultado: 15/06/2017].

Chueca Goitia, Fernando, Breve historia del urbanismo, Madrid, Alianza Editorial, 1968.

Chueca Goitia, Fernando y Torres Balbás, Leopoldo, Planos de ciudades iberoamericanas y filipinas existentes en el Archivo de Indias, Madrid, Instituto de Estudios de Administración Local, 1981.

Crispiani, Alejandro, «Richard Morse en el espejo de América Latina», Bifurcaciones. Revista de Estudios Culturales Urbanos, 3, Talca, 2005, http://www.bi 
furcaciones.cl/2005/06/richard-morse-en-el-espejo-de-america-latina/ [Consultado: 7/10/2017].

Delgado Viñas, Carmen, «Miradas sobre la ciudad desde la geografía, la historia y el urbanismo. El estado de la cuestión a comienzos del siglo XXI», Ciudades, 19, Valladolid, 2016, 117-142.

Fernández Águeda, Beatriz, «Del límite de la urbanización al límite de lo urbano: la construcción territorial del Gran París y el Gran Madrid (1910-1939)», Ciudades, 19, Valladolid, 2016, 31-56.

González Lebrero, Rodolfo E., La pequeña aldea. Sociedad y economía en Buenos Aires (1580-1640), Buenos Aires, Editorial Biblos, 2002.

González Reynoso, Arsenio, «Los estados de la cuestión sobre la investigación urbana en América Latina (1990-2000)», Anuario Americanista Europeo, 1, CEISAL-REDIAL, 2003, 133-146.

González-Varas, Ignacio, Conservación de Bienes Culturales. Teoría, historia, principios y normas, Madrid, Manuales Arte Cátedra, 2005, 4. ${ }^{\text {a }}$ edición.

Gunn, Simon, «Los poderes de la ciudad: nuevas perspectivas en la Historia Urbana», Urban. Historias Urbanas / Urban Histories, 06, Madrid, 2013, 101 110. http://polired.upm.es/index.php/urban/article/view/2056/2103 [Consultado: 5/10/2017].

Gutiérrez, Ramón, Arquitectura y urbanismo en Iberoamérica, Madrid, Cátedra, 1983.

Gutiérrez, Ramón, «Jorge Enrique Hardoy: su aporte a la historia urbana de América Latina», Revista Eure, XXI, 62, Santiago de Chile, 1995, 9-15.

Hardoy, Jorge E., Ciudades Precolombinas, Buenos Aires, Ediciones Infinito, 1964.

Helguera, J. León, «Guillermo Hernández de Alba (1906-1988)», The Hispanic American Historical Review, 69, 4, Duke University Press, 1989, 747-749.

Lempériere, Annick, «La historia urbana de América Latina. De las reformas borbónicas a los centenarios de la independencia», en Sosa, Ignacio y Connaughton, Brian (coords.), Historiografía latinoamericana contemporánea, México, UNAM, 1999, 73-135.

Lepetit, Bernard, «La historia urbana en Francia: veinte años de investigaciones», Secuencia. Revista de Historia y Ciencias Sociales, 24, México, 1992, 5-28.

Mandelbaum, Seymour, J., «H. J. Dyos and British Urban History», The Economic History Review, 38, United Kingdom, 1985, 437-447.

Mena García, Carmen, «Historia urbana hispanoamericana en Revista de Indias (1940-1989)», Revista de Indias, XLIX, 187, Madrid, 1989, 613-625.

Miranda Pacheco, Sergio, «La Historia Urbana en México. Crítica de una historiografía inexistente», en Quiroz Rothe, Héctor y Maya Pérez, Esther, Urbanismo. Temas y tendencias, México, UNAM, 2012, 349-361.

Monti, Alejandra, «La enseñanza de la planificación en la Argentina: Jorge Enrique Hardoy, del IPRUL al CEUR (1962-1976)», Anuario del Instituto de Estudios Histórico Sociales (IEHS), 29-30, Buenos Aires, 2014-2015, 177-195. 
Morales, María D.; Ros, María A. y Sánchez, Esteban, «La Ciudad de México, 1521-1857. Balance historiográfico», en Serrano Álvarez, Pablo (coord.), Pasado, presente y futuro de la historiografía regional en México, México, Instituto de Investigaciones Históricas, UNAM, 1998.

Morse, Richard M., La investigación urbana latinoamericana: tendencias y planteos, Buenos Aires, Ediciones SIAP, 1971.

Mumford, Lewis, The City in History, New York, Harcourt, Brace and World, 1961. [Ed. en castellano: La Ciudad en la Historia. Sus orígenes, transformaciones y perspectivas, Buenos Aires, Ed. Infinito, 1966].

Panadero Moya, Miguel, «El proceso de urbanización de América Latina durante el período científico-técnico. Bibliografía básica», Biblio 3 W. Revista Bibliográfica de Geografía y Ciencias Sociales, 298, Barcelona, 2001, http://www. ub.edu/geocrit/b3w-298.htm [Consultado: 23/11/2017].

Pradilla, Emilio y Jiménez, Carlos, Arquitectura, urbanismo y dependencia neocolonial, Buenos Aires, SIAP, 1973.

Romero, José Luis, Latinoamérica: las ciudades y las ideas, Argentina, Siglo XXI editores, 1976.

Romero, José Luis y Romero, Luis Alberto (dirs.), Buenos Aires. Historia de cuatro siglos, Buenos Aires, Editorial Abril, 1983.

Rueda Cáceres, Liliana y Plata Quezada, William Elvis, «Hacia un estado del arte de la historia urbana en Colombia: el caso de Bogotá», Apuntes. Revista de Estudios sobre Patrimonio Cultural, 29 (2), Bogotá, 2016, 56-69, http://dx. doi.org/10.11144/Javeriana.apc29-2.eahu [Consultado: 13/06/2018].

Sambricio, Carlos, «De los libros de viajeros a la historia urbana: el origen de una disciplina», en Sambricio, C. (ed.), «La Historia Urbana», Ayer. Revista de Historia Contemporánea, 23 (3), Madrid, 1996, 61-85, https://www.ahistcon. org/PDF/numeros/ayer23_LaHistoriaUrbana_Sambricio.pdf [Consultado: 13/03/2017].

Schávelzon, Daniel, «Jorge Hardoy y la preservación patrimonial», Medio ambiente y urbanización, 45, Buenos Aires, 1993, 96-102.

Segre, Roberto (relator), América Latina en su arquitectura, México, UNESCO, Siglo XXI editores, 1975.

Segre, Roberto; Cárdenas, Eliana y Aruca, Lohania, Historia de la Arquitectura y del Urbanismo: América Latina y Cuba, La Habana, Ed. Pueblo y Educación, 1986.

Socolow, Susan y Hoberman, Louisa, Cities and Society Colonial Latin America, Alburquerque, University of New Mexico Press, 1986.

Terán, Fernando de, «Historia urbana moderna en España. Recuento y acopio de materiales», en Sambricio, C. (ed.), «La Historia Urbana», Ayer, 23 (3), Madrid, 1996, 87-107, https://www.ahistcon.org/PDF/numeros/ayer23_ LaHistoriaUrbana_Sambricio.pdf [Consultado: 20/03/2017]. 